\title{
Tabula rasa como estrategia de investigación arquitectónica para la revolución 4.0
}

\author{
Tabula rasa as Architectural Research Strategy \\ for the 4IR
}

\author{
Prof. Juan R. Castillo Molina, Dr. Eng. \\ PJc8589@unphu.edu.do — https://orcid.org/0000-0001-5975-4307 \\ Universidad Nacional Pedro Henríquez Ureña, República Dominicana
}

Fecha de recepción: 15 de mayo de 2020

Fecha de aceptación : 1 de junio de 2020

Fecha de publicación: 30 de junio de 2020

\section{RESUMEN}

La tabula rasa es un recurso que reacciona ante el statu quo de la arquitectura, es algo que impacta la contemporaneidad y que acompaña la práctica de investigación. El objetivo del presente artículo es establecer la tabula rasa como detonante de pensamiento propio en investigaciones arquitectónicas a través de la definición de tres aspectos disruptivos: realidad, radicalidad y universalidad. Como resultado, se explica que la tabula rasa es una estrategia de investigación efectiva basada en un proceso de abordaje, enajenación, improvisación y ensamblaje del conocimiento, siendo esta una táctica eficaz para acompañar la fase avanzada de la educación arquitectónica iniciada por la Cuarta Revolución Industrial 4.0.

Palabras clave: aprendizaje, arquitectura, conocimiento, originalidad, radicalidad, tabula rasa.

\begin{abstract}
Tabula rasa is an effective conceptual resource that reacts against the statu quo in architecture, it impacts the contemporary milieu and support research practices. The objective of the present article is to set the concept of tabula rasa as the origin of critical thinking in architectural research through the definition of three disruptive aspects in architecture: reality, radicality and universality. As a result, it is explained how tabula rasa is an effective research strategy in architecture through processing engagement, detachment, improvisation and assemblage of knowledge, which is significant for supporting the advanced phase of architectural education that has already started with the Fourth Industrial Revolution (4IR).
\end{abstract}

Keywords: architecture, knowledge, learning, originality, radicality, tabula rasa. 


\section{Introducción}

La tabula rasa es el plano de acción vacío preparado para ser enriquecido con conocimiento previo y eventualmente detonar descubrimientos. En arquitectura, es un espacio intelectual donde se evitan referencias directas que manipulen el proceso de pensamiento, y por ser un lugar conceptual exige abstracción. La academia arquitectónica, consciente de la realidad de la profesión, puede conducir a los estudiantes hacia un pensamiento propio utilizando recursos disruptivos como la tabula rasa. La contemporaneidad ha revelado el statu quo de la arquitectura, pues el mercado y la industria de la construcción han dominado la producción arquitectónica desde hace décadas, ofreciendo una perspectiva limitada del ejercicio. Las escuelas frecuentemente «enseñan con el ejemplo», entrando raras veces en el territorio de lo radical por miedo a formar estudiantes fuera de lo que se percibe como «realidad»; pero la $t a-$ bula rasa es una alternativa que puede inducir a los estudiantes a crear sus propias visiones, y así enfrentar los retos que el «ejemplo» por sí solo no puede resolver. Un enfoque original que ayuda a enfrentar los cambios drásticos que el siglo XXI ha comenzado a imponer.

El presente artículo establece la tabula rasa como detonante de un pensamiento propio en arquitectura. Lo radical, base de la tabula rasa, ha tenido una historia difícil desde el pasado milenio, pues estuvo representado por vanguardias que desmontaban lo establecido a través de resultados iconoclastas, fomentando una ruptura total con la cultura milenaria de la humanidad. Pero lo radical siempre ha estado conectado con la historia, y ha pasado a ser una especie de «establishment» (cultura oficial) gracias a la modernidad. En este artículo, la tabula rasa se define a través de la realidad, radicalidad y universalidad como conceptos que han estructurado la historia de las civilizaciones. Consecuentemente, se explica que la tabula rasa como estrategia de investigación fomenta un proceso de abordaje, enajenación, improvisación y ensamblaje del conocimiento que acompaña la fase avanzada de la educación arquitectónica que la Cuarta Revolución Industrial 4.0 insiste en establecer.

\section{Realidad}

La realidad es todo aquello autoevidente que no necesita contradicciones para demostrarse. Usualmente, la realidad equivale a lo tangible, el cual es objetivo y absoluto en términos materiales independientemente de las percepciones que puedan forjarse alrededor de él. En la investigación arquitectónica, la realidad representa lo que está literalmente hecho, pero eso viene con una penalidad para los que buscan otras alternativas, pues aquello que «ya está realizado» se impone usualmente como única forma de hacer las cosas, convirtiendo todo lo que esté fuera de esa «realidad» en utopía. Esa es una resolución peligrosa para las escuelas de arquitectura, pues le niega la oportunidad de experimentación a aquellos estudiantes que quieren investigar ideas fuera del marco tradicional, y frena a aquellos profesores visionarios que quieren evolucionar el programa de la escuela hacia fronteras académicas imprevistas. La realidad es un hecho que conecta individuo y contexto, pero no debe ser un absoluto.

La realidad está basada en un statu quo que demora la materialización y aceptación de ideas en incubación. En el proceso, la repetición de soluciones que una vez fueron ingeniosas va creando fórmulas replicables evitando que la sociedad exija alternativas diferentes. La realidad se acomoda a la industria, sector acostumbrado a formar sistemas que aumenten la plusvalía de inversiones, y raras veces concuerda con la cultura, base de la humanidad que se mantiene en constante enfrentamiento contra los sistemas establecidos; es decir, la cultura no es solo tradición, también es una evidencia de las transformaciones radicales de las comunidades (Benjamin, 2012).

La realidad debe encontrar un lugar en la tabula rasa, en vez de implantar limitaciones 
que coarten el surgimiento de ideas inéditas, pues hay otra realidad, y es la de la tecnología automática (digital/virtual y programada) que transforma la arquitectura más allá de sus límites físicos. En la arquitectura construida o dibujada, el espacio para la imaginación es constreñido por la apariencia de la forma que limita lo diseñado -el aspecto visual predeterminado; pero en los momentos que lo virtual desmaterializa lo morfológico, surgen elementos incompletos que motivan al interlocutor o usuario a completar la obra con su propia imaginación; es decir, en esa otra realidad que esa tecnología promete, lo convencional o lo aprobado no pueden imponer sus absolutos (Jullier, 2004). De esta manera se explora una arquitectura como oficio que absorbe varios campos disímiles, permaneciendo abierta a medios que impacten la sociedad. La tabula rasa, como plano de acción, puede usar esa tecnología para disolver los límites entre disciplinas y producir algo que sobrepase las expectativas materiales.

Si la realidad está basada en lo evidente, lo tangible y lo inevitable, también tiene valor estético, aunque este último hecho permanezca latente para la mayoría de las civilizaciones. Todo cuanto rodea los ambientes humanos tiene forma definida con cualidades que afectan la cotidianidad, lo cual se hace evidente cuando se interactúa con los paisajes culturales (ciudades) y naturales (panoramas). El deseo de llamar a un sitio «lugar» deviene por las características sensuales del mismo, especialmente por aquellas que promueven confort y bienestar. Detrás y delante de todo ese ensamblaje está la estética, que intencional o accidental, inspira la formación de un conjunto de productos humanos que se denomina cultura (Barber, 2006). En el plano limpio de la tabula rasa, la realidad estética del mundo encuentra una oportunidad para revisarse, contribuyendo a la frenética costumbre de formulación de conocimiento de la sociedad contemporánea. Aunque esto último suene problemático, es realmente la razón de existencia de las tecnologías de la
Cuarta Revolución Industrial 4.0 empeñadas en sistematizar y conectar la carga de información cultural.

Hay una costumbre de conectar la enseñanza e investigación arquitectónicas con la realidad, y no es que hay que desconectar la academia de lo que sucede en la práctica, sino que hay que buscar vías de aplicación del conocimiento crudo que surge en las escuelas (Castillo Molina, 2019). Mantener la realidad como guía principal es engañoso, pues las realidades de cada comunidad nunca están resueltas solo por los limitados recursos que la práctica puede proveer, sino por las estrategias visionarias de aquellos que pueden ver más allá de las problemáticas fundamentales y utilizar la tabula rasa para llegar a soluciones insólitas. Por ejemplo, el surgimiento de métodos constructivos vernáculos no viene solamente por repetición de patrones existentes, pues también surge por un ajuste experimental; una forma de investigación empírica que implementa soluciones accidentales promovidas por la radicalidad.

\section{Radicalidad}

Lo radical viene con un optimismo genuino e ingenuo y con una franqueza incontestable. Lo radical es una respuesta humana a las crisis y es impulsado por visionarios. La visión es un legado, y el patrimonio de la humanidad se manifiesta a través de un planteamiento progresista acompañado de un comienzo fomentado por la tabula rasa. Al introducir este tipo de tácticas en los procesos de investigación arquitectónicos, la arquitectura se convierte en una profesión visionaria por naturaleza - un campo de soluciones a través de la imaginación.

La transcripción literal de la imagen a la realización es uno de los problemas de la radicalidad en arquitectura si no se interpreta cuidadosamente. En lo radical, dibujo y concepto son una unidad cógnito-visual que funciona como propuesta válida inmediata. Las innovaciones radicales para el presente milenio deben ser cuidadosas de las imágenes que proyectan, 
pues quienes materializan el ambiente construido (no necesariamente arquitectos) las usarán como guía inmediata. Por ejemplo, el arquitecto Ludwig Hilberseimer propuso en 1927 el proyecto Ciudad Vertical con imágenes que representaban una ciudad objetiva y desprovista de ornamento alguno, representada a través de perspectivas lineales (recurso abstracto del movimiento Nueva Objetividad) que no aclaraban si las ilustraciones eran para implementarse o intelectualizarse; sin embargo, parte de su visión de ciudad sirvió más tarde de modelo de viviendas de bajo costo convirtiendo su trabajo en la antítesis del bienestar moderno, de forma que cualquier contribución arquitectónica fue desconsiderada debido a la crudeza de las imágenes (Anderson, 2013).

La radicalidad se asocia usualmente con lo iconoclasta, y aunque esa fue la estrategia de las vanguardias artísticas del siglo XX (Kuenzli, 2006), aún sigue vigente en arquitectura a pesar de que los estilos arquitectónicos que se están implementando desde finales del pasado milenio han introducido el concepto de «diferenciación continua», es decir, la transición gradual de un sistema a otro como por ejemplo lo propone la topología geométrica (Schumacher, 2008). Aunque hoy se habla de alternativas o posibilidades, el plano limpio de la tabula rasa transforma radicalmente las tradiciones en rutas originales.

La estética de la radicalidad contrarresta aquellas que prevalecen y gobiernan la sociedad. Ese fenómeno es una necesidad primaria en tiempos de la incertidumbre producida por el statu quo de la profesión, pero advierte que la estética radical podría ser tiránica si no se procesa a través de un plano limpio como el que ofrece la tabula rasa que en sí facilita la reflexión y experimentación antecediendo la implementación (Papadakis, 1992). Aunque el ambiente construido trae consigo una estética, esta última, si es radical, escapa del confinamiento físico y pasa al plano de la imaginación sacudido por la imposibilidad de conectar lo real y lo drástico.
Esta dinámica siempre podrá ser verificada por la experiencia que es lo que conecta la tabula rasa con el contexto donde se aplica.

En cuanto a la investigación arquitectónica, lo radical plantea una transposición de funciones y estrategias para los estudiantes que aumentan las posibilidades de conseguir originalidad, como lo expresó Paul Virilio (1988) «la estética de la investigación reemplaza a la investigación de una estética, la estética de la desaparición renueva la aventura de la apariencia». Las manifestaciones estéticas de la radicalidad son liberadoras al ponerse contra el plano vacío de la tabula rasa, pues cada quién construye sus propias expresiones migrando naturalmente o artificialmente hacia el mundo de las tecnologías de la Cuarta Revolución Industrial 4.0, que facilita la diseminación de ideas envueltas en formato universal.

\section{Universalidad}

La universalidad es una construcción de la cultura humana. Las civilizaciones dominantes han implantado sistemas que apelan a lo omnipresente luego que la especie tuvo la necesidad de aglomerarse y crear lo que hoy se conoce como asentamientos humanos. Esos sistemas son seductores, logrando que las culturas cambien sin darse cuenta de que han pasado por una tabula rasa, es decir, como esos códigos foráneos apelan efectivamente al sentido de humanidad, su implantación es inmediata, aunque su aceptación demore. Así la universalidad hace vigente la tabula rasa en las estructuras sociales mundiales.

La universalidad desea lo infinito. Estructurar algo que intente ser universal es difícil porque eso aspira a una aplicación longeva. Lo universal es ajeno a lo efímero, pues el tiempo que toma en convertirse en universal exige que su aplicación se mantenga vigente mientras exista la necesidad de progreso humano (Marina, 2007). En este sentido, lo avanzado y la universalidad comparten lo infinito, pues por un lado mantienen rutas abiertas hacia el futuro, y por 
otro, dan la oportunidad de comenzar desde cero cada vez que sea necesario (Sigurdsson, 1995). Así lo infinito apela a lo ilimitado, permitiendo que las experimentaciones incluyan propuestas aparentemente absurdas que tomen forma en el plano vacío que ofrece la tabula rasa.

La universalidad establece un código obligatorio. Para ser universal se necesita que sus características y valores sean reconocibles aún en situaciones primerizas. Los códigos son precisamente unidades que pueden pasar de una cultura a otra manteniendo su estructura intacta; es sólo al momento de descifrarlos que se necesitan medios que puedan traducirlos a significados locales (Reas and McWilliams, 2010). Así el código universal deviene obligatorio no por imposición sino por seducción intelectual y por optimismo resiliente innatos de la tabula rasa.

En arquitectura, la universalidad está representada por tres elementos que han acompañado el código de la misma desde su origen: armazón, cascarón y vacío. Estos tres elementos han estado y estarán presentes en todas las posiciones arquitectónicas indistintamente de su fuente cultural y objetivo estético. El armazón es lo que literalmente sostiene a la arquitectura, y está definido por uso y estructura, fungiendo como aquello que mantiene la obra en operación. El armazón le da universalidad a la tabula rasa en la medida que la disocia de corrientes en boga, y en la manera que la aborda a través del contexto físico y no necesariamente a través de la idiosincrasia de los pueblos, es decir, al ser un ente físico puede reusarse indefinida e indistintamente del propósito original que le dio forma. El cascarón define el exterior e interior de la arquitectura y siempre estará conectado a una época histórica de la profesión, pero le da universalidad a la tabula rasa cuando se transforma en el legado de una comunidad. El vacío es el volumen interior habitable que soporta la capacidad de abstracción de la arquitectura, dotando de universalidad a la tabula rasa a través de las herramientas que la Cuarta Revolución Industrial 4.0 ofrece. De esta manera, la tabula rasa admite análisis lúcidos y realistas de esos tres aspectos (armazón, cascarón y vacío), evitando manifiestos y propuestas vagas, y llegando a esquemas radicales a través de los medios emergentes a disposición (Sans y Sanchez, 2001).

\section{Tabula rasa para el siglo XXI}

Promover formas de investigación utilizando la tabula rasa siempre será arriesgado porque comenzar desde un plano de acción vacío es intimidante. La especie humana cultiva la continuidad del conocimiento, mientras que la tabula rasa exige que se aborde una investigación sin hipótesis, suspendiendo el conocimiento temporalmente hasta que sea necesario recuperarlo y utilizarlo. Esto es disruptivo, y como tal, posiciona al investigador fuera de la seguridad intelectual que el conocimiento acumulado provee. Pero para canalizar las frustraciones profesionales que el statu quo de la arquitectura infiltra, es necesario arrancar desde una superficie limpia que evidencie lo inoperante, que permita que nuevos fracasos surjan y finalmente que indiquen rutas alternativas hacia descubrimientos insólitos que evolucionen la profesión.

Crudamente, la tabula rasa evita las hipótesis, pero facilita un plano limpio para que sea el análisis, figura de investigación universal, el que lidere el comienzo de la pesquisa. Producir conceptos visionarios es difícil porque se trata de un esfuerzo constante hacia la originalidad, algo que no se puede perseguir directamente sino bajo cuestionamientos recurrentes y elípticos; elípticos porque hay que desconectar la idea del torbellino intelectual para trabajar con la pureza de la misma (Moholy-Nagy, 1929).

La tabula rasa en arquitectura usualmente trabaja con la imagen del proyecto (lo que se «ve»), y sólo se profundiza en los aspectos intelectuales (lo que se piensa e imagina) luego que la estética hace su impacto y despierta interés. Estética es en gran parte la expresión tangible de la arquitectura, aquello que es obvio para el ojo del público general, aquello que le advierte que algo original ha surgido. Los académicos 
pueden tratar los hallazgos conceptualmente, pero se necesita pasar a las representaciones de esos conceptos (dibujos, modelos, imagen en movimiento u obra construida) para llegar a una audiencia amplia, inspirar futuras generaciones y demostrar el nivel de innovación alcanzado (Deleuze, 2004).

La tabula rasa es parte de la evolución de la humanidad, aunque solo se perciban sus manifestaciones drásticas, aquellas que toman el descubrimiento y lo disocian de las maneras antiguas. Por ejemplo, hoy se habita en rascacielos porque hubo un replanteo radical en los estilos de vida urbanos, convirtiendo eventualmente a la tabula rasa en ejemplo de la cultura local, aunque eso no haya sido parte de su programa inicial. Cuando la ruptura aparece, el primer movimiento del historiador es buscar rastros que la conecten con la historia, todo por el afán humano de estar conectado a un origen ancestral, pero la tabula rasa no funciona así. Los dadaístas descubrieron lo radical como elemento reformador de ideas, y empeñados en demostrar su eficiencia, lo usaron como estrategia para suspender viejas costumbres artísticas e instauraron la tradición de lo nuevo en la modernidad (Richter, 1964). Luego de los años 60, y debido a la mala implementación de las soluciones modernas, la cultura occidental tomó al historicismo, movimiento que repetía los cánones clásicos como valor inequívoco de la profesión, para rechazar propuestas que estéticamente estaban conectadas a la innovación y para crear desconfianza en la experimentación de ideas inusuales. Aunque el siglo XX haya tenido una mala experiencia con la tabula rasa, eso no debe frenar al presente milenio a revisar la efectividad de esa estrategia disruptiva, especialmente cuando la Cuarta Revolución Industrial 4.0 provee herramientas para que eso se lleve a cabo en un plano seguro -la virtualidad (Figgis, 2008).

El reto de la enseñanza hoy día es despertar el interés de los estudiantes en los aspectos que se discuten en el curso; si se logra inculcar ese interés, se inicia un proceso de aprendiza- je ascendente y casi automático donde la labor docente va más allá de transmitir conocimiento. La tabula rasa es efectiva en este proceso pues lleva al estudiante a partir de su propia perspectiva, en vez de continuar fielmente indicaciones preestablecidas. Siempre hay un contexto cultural contra el cual hay que poner a prueba las nuevas ideas, y es en esa dinámica donde lo existente cobra valor para negarse, transformarse o cambiarse y para servir como palanca de un recomienzo total. Y no se trata de que la educación se convierta en la eliminación de todo lo aprendido, sino que paralelamente a las asignaciones tradicionales haya ejercicios que planteen un nuevo punto de partida que cuestione el conocimiento adquirido; deben darse documentaciones básicas, pero no las formas de cómo manipularlas pues eso debe venir del alumno -así también funciona la tabula rasa.

Parte de la investigación en arquitectura no está basada en procesos científicos sino en conceptos, pues las ideas arquitectónicas no responden al cálculo solamente sino a necesidades universales, por lo tanto, su investigación requiere un formato distinto a las científicas que demuestre la importancia de la innovación en cuestión y no necesariamente que compruebe una hipótesis (Feyerabend, 2008). Por otro lado, hay que evitar que la innovación radical se quede en manos de universidades extranjeras, pues también hay que encargarse de las visiones propias puedan tener un impacto global, aunque hayan surgido de necesidades locales. En este caso, es relevante pensar conceptualmente para discutir en un plano sin prejuicios como lo provee la tabula rasa, y aunque los conceptos sean radicales, y posiblemente ajenos a las costumbres locales, deben estar expuestos claramente para que puedan implementarse, por lo tanto, hoy más que nunca es imprescindible confiar en la objetividad que puede encontrarse en el plano vacío de la tabula rasa. Cuando se trabaja con la tabula rasa, se explora todo desde la intuición, la objetividad, la lógica hasta el azar; todos los conceptos tienen oportunidad en ese 
plano vacío. Las acciones básicas que se ejecutan en la tabula rasa son primero abordaje, pues se debe manejar a la perfección aquello que se desea desplazar. Segundo, enajenación, pues se debe salir intencionalmente del tema bajo estudio para ver otros horizontes. Tercero, improvisación, pues debe aprovechar la libertad de lo desconocido para descubrir soluciones impensables; y por último, ensamblaje, pues debe componer los hallazgos en un plan óptimo que evite utopías. El abordaje y la enajenación funcionan bajo la razón e intuición, la improvisación trabaja con el accidente, mientras que el ensamblaje se guía de la objetividad y claridad necesarias para dar sentido a ideas drásticas. Para conectar esas acciones con la Cuarta Revolución Industrial 4.0 en la tabula rasa es necesario asumir los siguientes puntos:

1. El abordaje debe ser a través de un análisis del contexto primario, siendo la red de información global el ambiente contemporáneo original. Toda asignación tiene un entorno que puede ser explorado usando la conectividad que la Industria 4.0 facilita. La información deviene en capas que existen simultáneamente y exigen herramientas que las organicen y las preparen para la recuperación posterior, pues el conocimiento siempre ha estado flotando en el mundo virtual, es latente y su potencia aumenta con la interconexión. Eso facilita que el abordaje de lo existente sea preciso para poder seleccionar cuáles datos necesitan ir llenando el plano vacío que la tabula rasa ofrece.

2. La enajenación es posible cuando el conocimiento existente se suspende, y aunque es una tarea difícil en un mundo con información omnipresente, las herramientas de la Cuarta Revolución Industrial proveen la distracción necesaria. Y esa es la clave, distraer temporalmente el asunto principal, sustituirlo por juegos, entretenimiento o arte; siempre y cuando mantengan al subconsciente conectado a la tarea principal (encontrar rutas originales) y puedan de alguna manera facilitar la conexión posterior con el sujeto bajo estudio. La disrupción principal sucede en este paso, y depende la intuición para mantenerse parte del proceso general.

3. La improvisación está dirigida por la aparente no-programación, aparente porque en los procesos de diseño el azar es esperado, es decir, programado para que suceda en algún momento, aunque no se sepa cuándo precisamente. Las herramientas de la Cuarta Revolución Industrial 4.0 precisan la improvisación, pues la inteligencia artificial, en su afán de devenirse casi humana, facilita búsquedas aparentemente al azar para el inexperto ingenio humano. La tabula rasa es el plano ideal para la improvisación, pues no importa cuantos intentos fallidos existan siempre habrá cabida para la solución original hallada a través del accidente.

4. El ensamblaje en la tabula rasa sucede como acción e intervalo paralelamente. Acción por la intensa selección de intentos llevados a cabo en la improvisación para alcanzar soluciones que tengan sentido con la innovación; y es intervalo porque existe entre el límite que ha interrumpido el abordaje y el límite que retoma lo que se necesita conservar. Como proceso final ejecutado en la tabula rasa, el ensamblaje es objetivo y puede utilizar la precisión de las tecnologías de la Cuarta Revolución Industrial 4.0 para interconectar equipos que persigan fines comunes y eventualmente difundir la relevancia de los descubrimientos.

La tabula rasa no es sólo una estrategia de aprendizaje académica, también es un proceso de la práctica arquitectónica preocupada por la innovación radical. Hay una oportunidad de negocio en esta última que aparentemente permanece oculta para aquellos que manejan el desarrollo de las ciudades, ya sea intencionalmente ignorada para no correr los riesgos que la misma conlleva, o culturalmente rechazada a favor de los beneficios inmediatos que trae la cotidianidad; para que la innovación radical sea efectiva en arquitectura debe impactar todas las industrias humanas responsables de la materialización del ambiente construido. 
Actualmente, las tecnologías de la Cuarta Revolución Industrial 4.0 han hecho que los desplazamientos culturales sean cada vez menores, pues se encargan de que el impacto humano de una parte del mundo transforme todo el planeta en tiempo exponencial, haciendo difícil que contextos disímiles permanezcan indiferentes ante cambios drásticos universales. Y dentro de esa dinámica, la tabula rasa ofrece una oportunidad hacia una mentalidad avanzada y sensible que introduzca rutas originales hacia la transformación de necesidades existenciales. Hoy día eso es una prioridad, pues la escala de las transformaciones intelectuales pasó de lo global a lo microscópico levantando nuevas incertidumbres que reiniciarán las bases culturales de la humanidad en el plano limpio de la tabula rasa.

\section{Referencias}

Anderson, R. (2013). Ludwig Hilberseimer: metrópolis architecture. Nueva York: GSAPP BOOKS.

Barber, S. (2006). Ciudades proyectadas: cine y espacio urbano. Barcelona: Editorial Gustavo Gili, SL

Benjamin, W. (2012). Imágenes que piensan. Madrid: Adaba Editores, S.L.

Castillo Molina, JR. (2019). Innovación y transferencia: la implementación del hallazgo. AULA Revista de Humanidades y Ciencias Sociales. 64 (4), 46-56.

Deleuze, G. (1929). La imagen tiempo: estudios sobre cine 2. Barcelona: Ediciones Paidós Ibérica, S.A.

Feyerabend, P. (2008). Adiós a la razón. Madrid: Editorial Technos (Grupo Anaya S.A.)

Figgis, M. (2008). El cine digital. Barcelona: Alba Editorial, s.l.u.

Jullier, L. (2004). La imagen digital: de la tecnología a la estética. Buenos Aires: La Marca.

Kuenzli, R. (2006). Dada. New York: Phaidon Press Inc.

Marina, JA. (2007). Las arquitecturas del deseo: una investigación sobre los placeres del espíritu. Barcelona: Editorial Anagrama, S.A.,
Moholy-Nagy, L. (1929). La nueva visión: principios básicos de la Bauhaus. Buenos Aires: Ediciones Infinito.

Papadakis, A. (1992). Theory + Experimentation. Architectural Design. Vol. 62. No. 11/12, November-December. pp.10-41. noviembre-diciembre 1992. London: Academy Group Ltd.

Reas, C. and McWilliams, C. (2010). Form and code in design, art, and architecture. New York: Princeton Architectural Press.

Richter, H. (1964). Dada Art and Anti Art. New York, NY: Thames \& Hudson, Inc.,

Sans, J. y Sánchez, M. (2001). Quel est le role de l'artiste aujourd'hui? Paris: Imprimerie Balauze et Marcombe, Cánejan.

Schumacher, P. (2008). Parametricism as style-parametricist manifesto. Recuperado el 15 de mayo 2020 en URL: https://www.patrikschumacher.com/Texts/Parametricism\%20as\%20Style.htm

Sigurdsson, S. (1995). Björk: Post. London: Bloomsbury Publishing.

Virilio, P. (1988). Estética de la desaparición. Barcelona: Editorial Anagrama, S.A.,

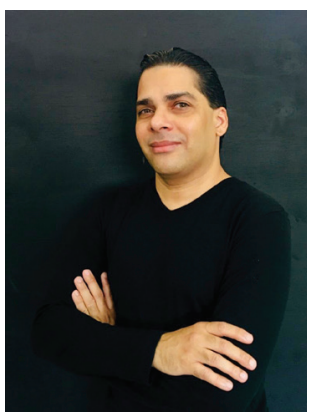

\section{Juan R. Castillo}

Arquitecto egresado de Arquitectura y Urbanismo (UNPHU, 1994), obtuvo Doctorado en Hiroshima University (Japón, 2002), jurado de maestría en Columbia University (USA, 2010), es profesor titular en la Universidad Iberoamericana (UNIBE), coordinador de Innovación Arquitectónica (UNPHU) y es editor jefe de la revista UMBRIEL de la UNPHU. Ha publicado en Journal of Architecture, Planning and Environmental Engineering (AIJ, Tokyo), Misawa Bauhaus Collection (Tokyo), Portal Docente UNIBE (República Dominicana) y Aula, revista de Humanidades y Ciencias Sociales (República Dominicana). Asociado a Shearly Investments, Inc., diseñó proyectos turísticos, habitacionales e industriales. Miembro del Architectural Institute of Japan (AIJ, Tokyo), CODIA y SARD (Santo Domingo), jurado concurso ADOACERO, y practica desde su firma FUTURA, Arquitectura Emergente SRL. 